\title{
MODELING OF COOLANT FLOW WITHIN THE SPENT FUEL STORAGE POOL OF A VVER 440 REACTOR
}

\author{
GÁLIK Gabriel ${ }^{1}$, KUTIŠ Vladimír ${ }^{1}$, JAKUBEC Jakub ${ }^{1}$, \\ PAULECH Juraj ${ }^{1}$, SEDLÁR Tibor ${ }^{1}$ \\ ${ }^{I}$ Slovak University of Technology in Bratislava, Faculty of Electrical Engineering and Information Technology, \\ Department of Applied Mechanics and Mechatronics, Ilkovičova 3, 81219 Bratislava, Slovakia, \\ e-mail: gabriel.galik@stuba.sk
}

\begin{abstract}
The article deals with modelling of coolant flow within the spent fuel storage pool of a VVER 440 reactor. The spent fuel storage pool is modelled in a state of standard reactor operation. The coolant heating from the remaining thermal power of stored spent fuel assemblies was also modelled.
\end{abstract}

KEYWORDS: CFD, Thermo-Hydraulics, BSVP

\section{Introduction}

The spent fuel storage pool is used for long term storage and cooling of spent fuel assemblies of the VVER 440 reactor. The intention of this paper is to model the steady state coolant flow within the storage pool. Computational Fluid Dynamics solutions were calculated using ANSYS CFX.

\section{Geometric model}

The spent fuel storage pool consists of the primary pool, two inlet pipelines located at the bottom of the storage pool, two outlet pipe lines located at the top, including the submerged reserve and storage grids and their support structures. The storage grid contains hexagonal absorbers around every fuel assembly storage location. The model contains spent fuel assemblies stored in all storage locations, 290 in total. The heat transfer through the solid walls of the absorbers and fuel assembly shroud was not modelled.

Although, the physical models describing the processes within the storage pool are relatively simple, the structures submerged within the pool are of highly complex design and geometry. Significant simplifications were necessary to save computing power and to speed up solution times. The reserve grid was removed from the model together with its supporting structure, as it is not present during standard operation. A number of details were simplified on the remaining structures that were deemed to have insignificant impact on flow profiles. Simplified fuel assemblies were used, where individual fuel rods in fuel assemblies were represented by an equivalent assembly model. 


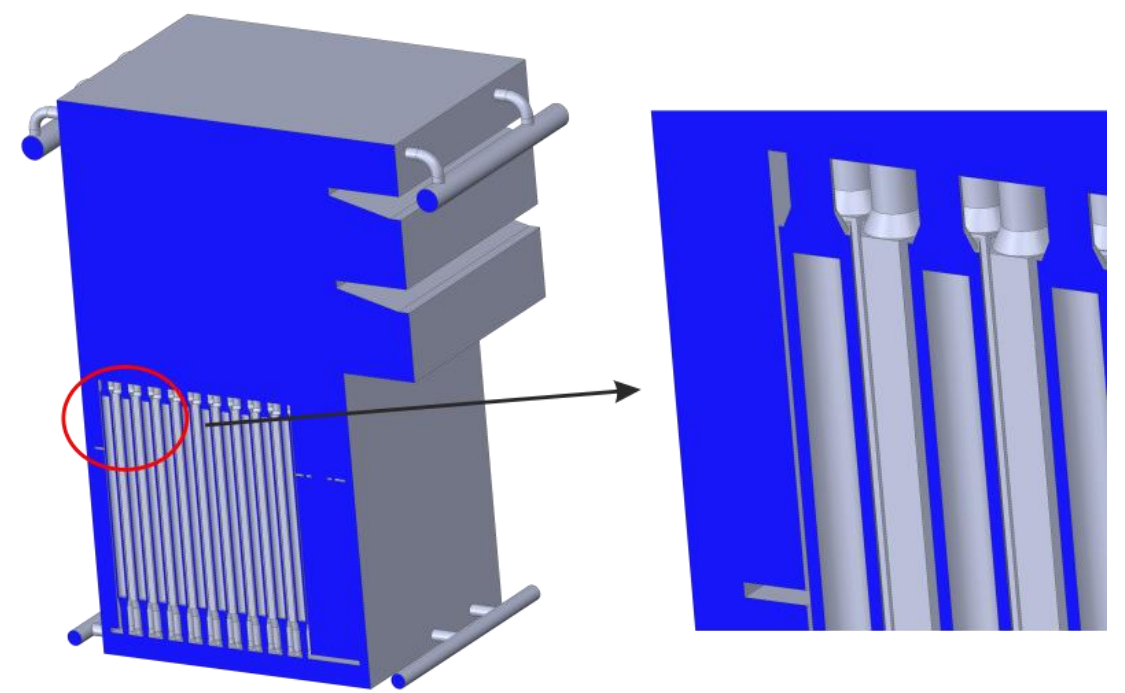

Fig. 1 Section of the final coolant volume model with a detailed view of fuel assemblies

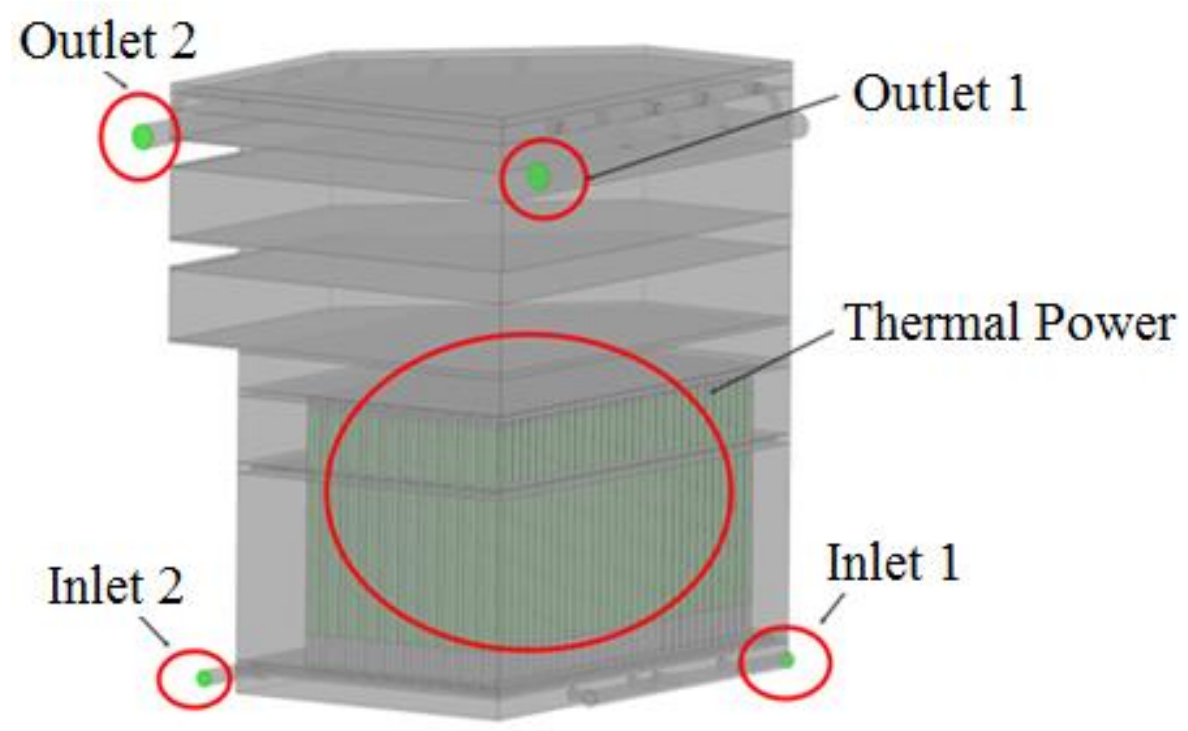

Fig. 2 Model and boundary conditions

\section{Boundary conditions}

Boundary conditions were set based on standard operational data. The total coolant level was $14.7 \mathrm{~m}$ above the reactor zero reference level. Nominal pump properties were set for total inlet mass flow (Inlet 1 and Inlet 2) values at $85.5 \mathrm{~kg} / \mathrm{s}$. The inlet coolant was injected at a constant temperature of $35{ }^{\circ} \mathrm{C}$. The total remaining thermal power of all stored fuel assemblies was $1.9 \mathrm{MWt}$, this power represents the thermal loading after reactor refuelling. All remaining faces were set to a "No Slip Wall" boundary condition, except the top horizontal face, which was set to a "Free Slip Wall" condition to simulate the properties of the free surface.

\section{Model discretization and numerical mesh}

The geometrical model was divided into multiple parts to ease the discretisation process. The resulting divided model is shown in Figure 3. 


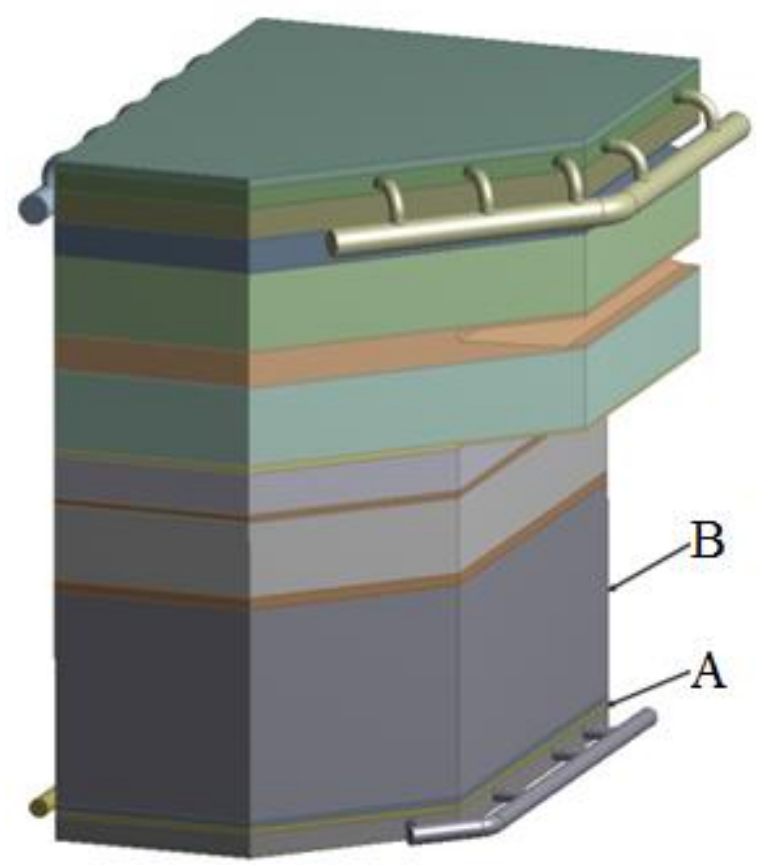

Fig. 3 Geometrical model division, location of parts A and B

The resulting parts were subsequently individually discretised using different meshing methods and elements. Two examples are marked in Figure 3 as A and B. Part A was meshed with tetra elements using Quick Delaunay method and it is shown Figure 4.

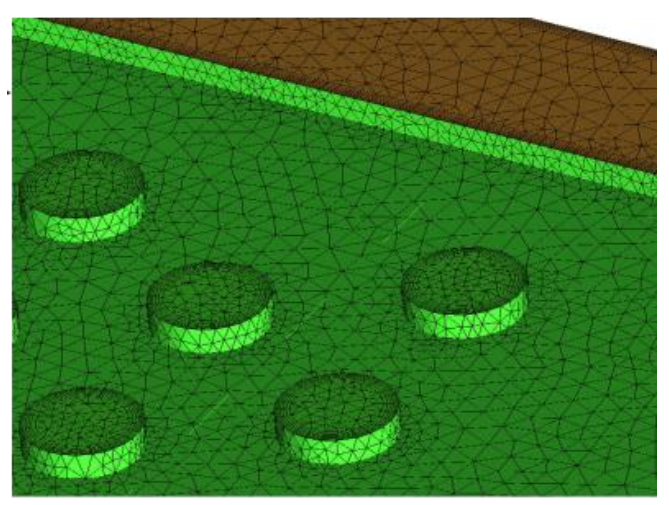

Fig. 4 Detailed view of part A tetrahedral mesh

Part B was meshed with hexagonal elements using multizone blocking method and it is shown in Figure 5

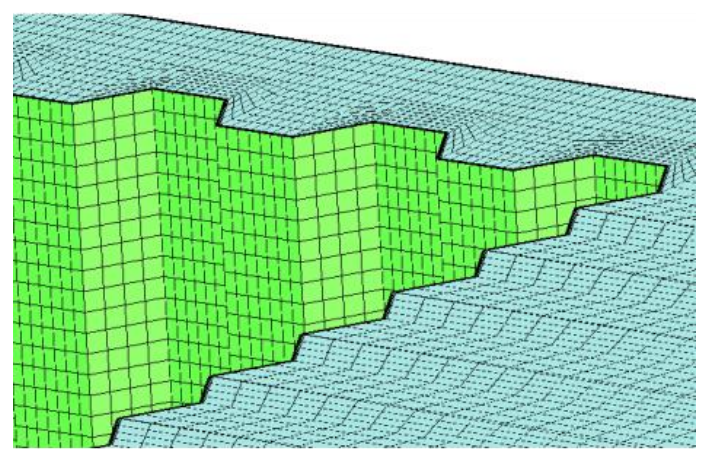

Fig. 5 Detail view of part B hexagonal mesh 
The total number of elements in the discretised model was app. 63.7mil., while the total number of nodes was app. 54.9 mil.

\section{CFD simulation}

The goal of the CFD simulation is to determine the steady-state coolant flow in the spent fuel storage pool. Shear stress transport (SST) turbulent model was used during the solution process. The settled mean value of average outlet fluid temperature was used as the condition for steady-state solution. This condition was fulfilled after 2145 iterations.

\section{Simulation results}

The distribution of temperature and flow velocities was calculated within the entire fluid domain. However, for clarity, three different section planes were used through rows 1, 6 and 13 (as shown in Figure 6), to represent the spatial distribution of given flow properties. Additionally, outlet streamlines of 7 selected fuel assemblies were analysed to characterise the fluid flow structure within the storage pool.

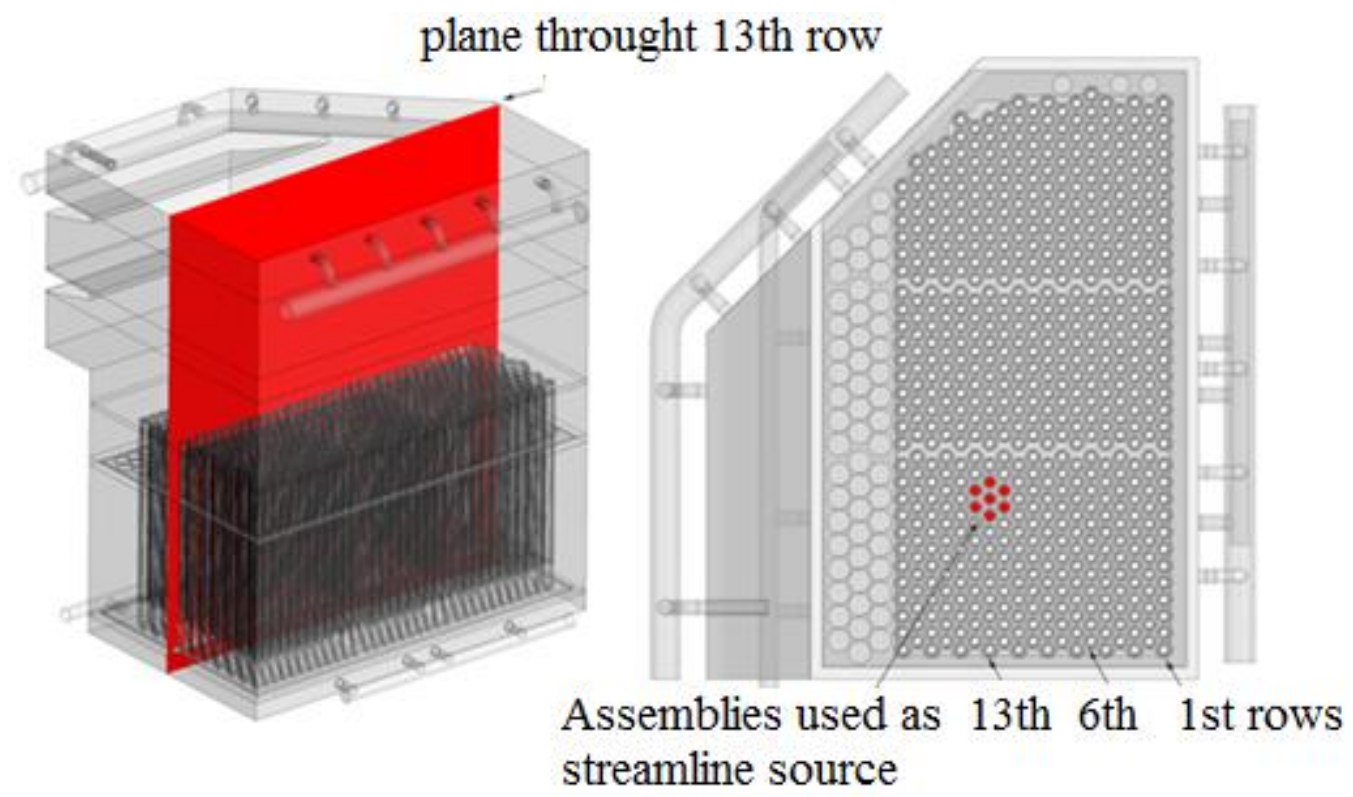

Fig. 6 Visualisation section planes and selected assemblies

Figure 7 shows the distribution of inlet streamlines with mapped flow velocities at the bottom of the pool. The mapped velocities show the approximate maximum flow velocity at the pool bottom to be $0.86 \mathrm{~m} / \mathrm{s}$. Additionally, the distribution of streamlines characterises the induced vortices during flow interaction. 


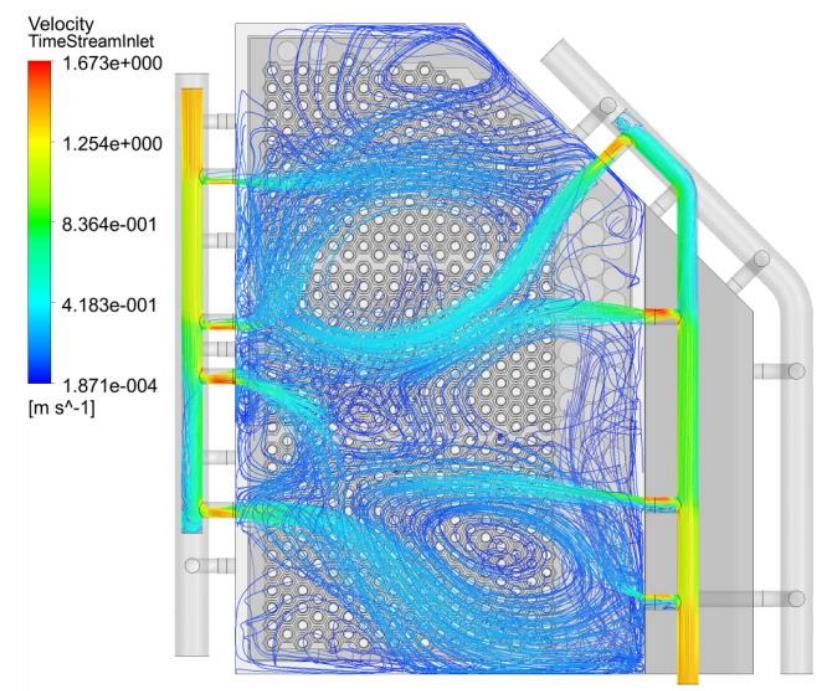

Fig. 7 Inlet streamlines with mapped flow velocity

Time on streamline can be calculated using the length and shape of a streamline together with flow velocities. This property represents the time required for the fluid to travel along the streamline to the given location as shown in Figure 8.

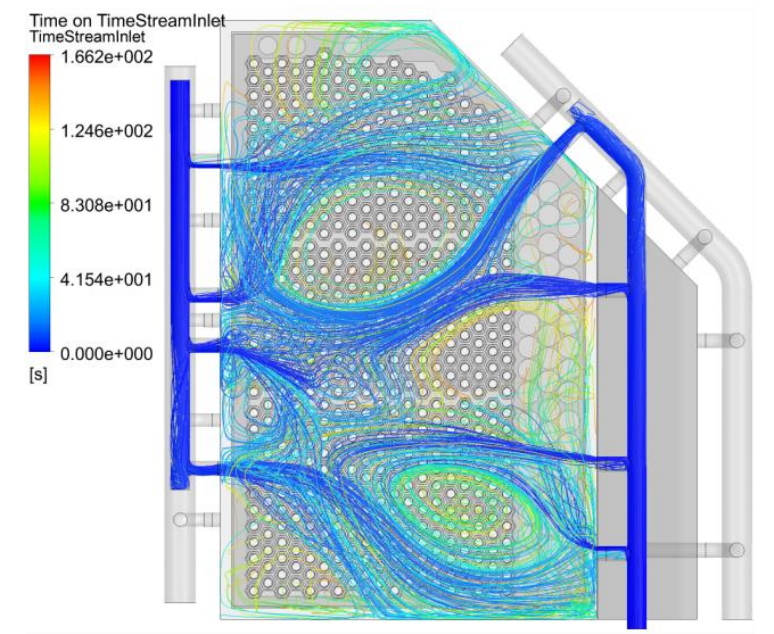

Fig. 8 Inlet streamlines with mapped time on streamline

Figure 9 shows streamlines originating from the 7 selected assemblies (shown in Figure 6), together with mapped Time on stream line property. As the mapped Time data shows, coolant exiting the selected assemblies remains within the storage pool for a relatively long time (2000s) before it enters the drain pipelines. The figure also shows streamlines that are part of a recirculation flow. 


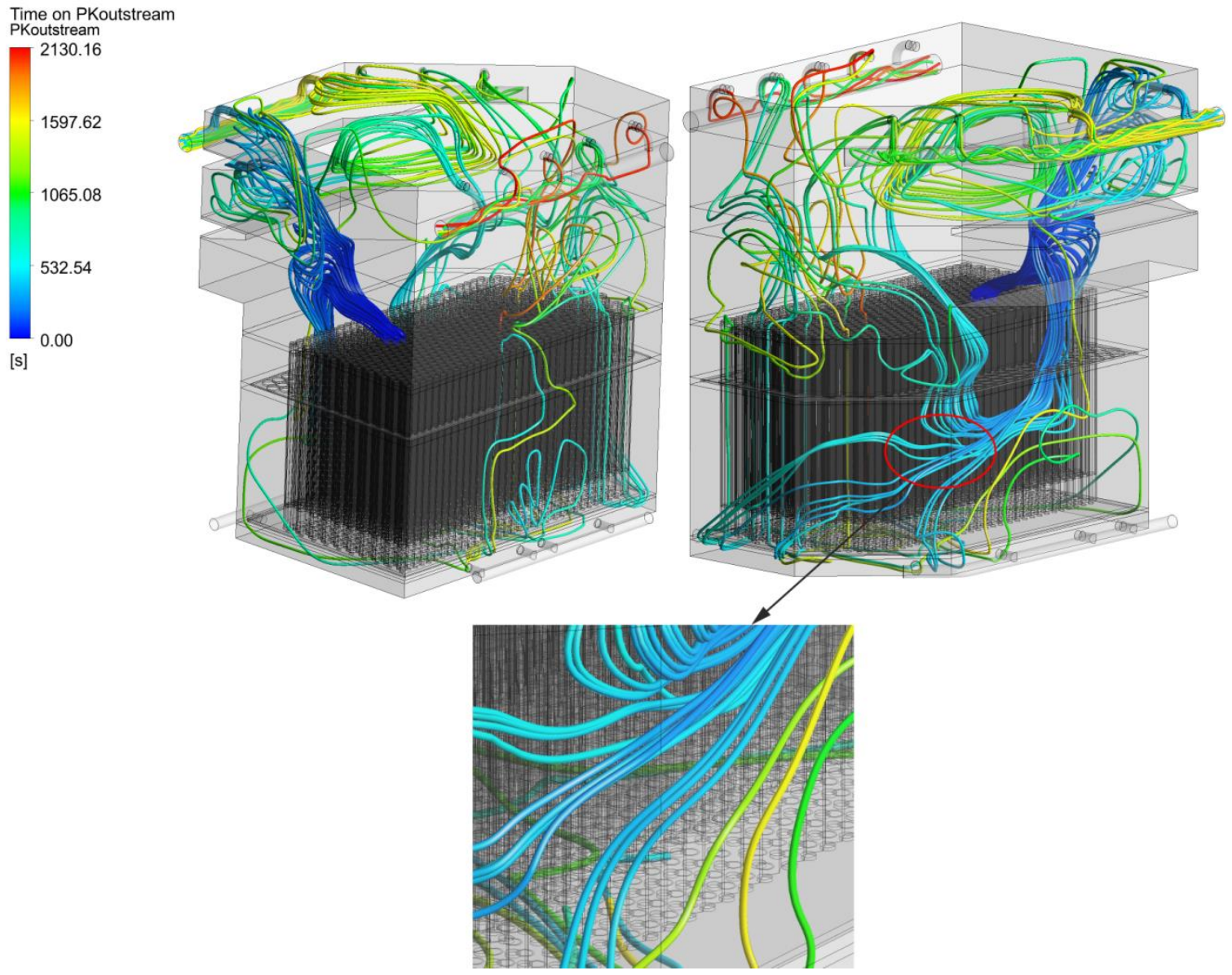

Fig. 9 Streamlines originating from 7 selected assemblies with mapped Time on streamline
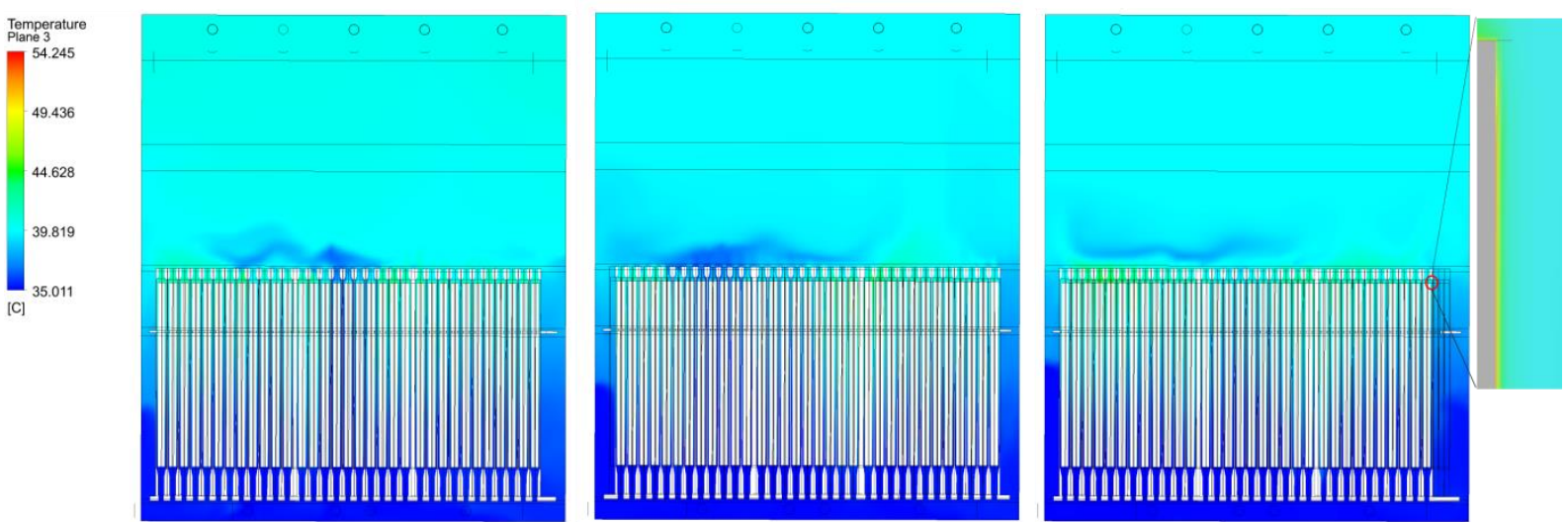

Fig. 10 Distribution of temperatures in the vertical section planes through stored assembly rows(1st 6th and 13th) with a detailed view of an equivalent fuel rod

Figure 10 shows the distribution of coolant temperature in the vertical section planes through rows 1, 6 and 13 (shown in Figure 6). Despite the equally distributed thermal power, the coolant temperature in stored assemblies is non-uniform. This is caused by different mass flow rates through individual assemblies. Local temperature maximums are formed in layers that are in direct contact with the fuel rods[3], as shown in the detailed view of Figure 10. 


\section{Conclusion}

Forced flow and buoyancy effects create comparatively low flow velocities. Such low flow velocities result in relatively large eddies, which cause the recirculation and mixing of the coolant fluid through fuel assemblies.

\section{ACKNOWLEDGEMENTS}

This work was supported by the Slovak Research and Development Agency under the contract No. APVV-0246-12 and APVV-14-0613, by Grant Agency VEGA, grant No. $1 / 0228 / 14$ and $1 / 0453 / 15$. Authors are also grateful to the HPC Centre at the Slovak University of Technology in Bratislava, which is a part of the Slovak Infrastructure of High Performance Computing (SIVVP project, ITMS code 26230120002, funded by the European Regional Development Funds), for the computational time and resources made available.

\section{REFERENCES}

[1] N. E. Todreas, M. S. Kazimi. Nuclear Systems Volume I: Thermal Hydraulic Fundamentals. CRC Press; 2 edition, 2011. ISBN 1439808872

[2] H. Versteeg, W. Malalasekera. An Introduction to Computational Fluid Dynamics: The Finite Volume Method. Prentice Hall; 2 edition, 2007. ISBN 0131274988

[3] V. Kutiš, J. Jakubec, J. Paulech, G. Gálik, T. Sedlár. CFD Analysis of Downcomer of NuclearReactor VVER 440. Journal of Mechanical Engineering - Strojnicky časopis, 2016 (66), No. 2, $55-62$. 
